\title{
E-du.c@c@o F1.51.C4: The Beginning of the Consolidation Process of the Pilot Project
}

\author{
Rodrigo Fukugauti \\ Comendador Emílio Romi State School (SEE/SP), São Paulo, Brazil
}

\begin{abstract}
This paper aims to analyze the implementation process of the pilot project “e-du.c@c@o F1.51.C4: an experience in hybrid learning", comparing the results obtained in the years 2016 and 2017. To accomplish this task, a bibliographical research, a documentary research, and a field research were carried out. In general, negative results were found in 2016 and positive results were found in 2017. All change generates strangeness, and however, the fact is that student resistance is being overcome. The consolidation process seems to have started and it is currently underway.
\end{abstract}

Keywords: physical education, hybrid learning, curricular restructuring

\section{Introduction}

The existing societal paradigms no longer attend to our needs, social challenges, and relationships, since a rupture in the idea of a work-related society has been taking place. A new idea has emerged that values an education structured by the culture of teaching, along with the concept of net society, in which education has been rebuilt, resulting in a new educational model based on the culture of learning (Behar, 2009).

In that sense, a new pedagogical field is taking shape, in which the development of skills and competencies, the creation of learning communities, the social networks, the respect for individual pace, and other characteristics are becoming increasingly present in the educational context (Behar, 2009).

The advent of information and communication technologies (ICT) has launched this change in paradigm, directing society towards a new way of living and a new set of references. That is, a new way of seeing, feeling, realizing, interpreting, and acting in the world (Behar, 2009).

This new paradigm, therefore, can be seen in every area of knowledge due to a process that has happened from the inside out. On the other hand, this process has happened the other way around in education, from the outside in, leading to a crisis in the traditional model through the decentralization process of the information brought by the ICT, resulting in a new institutional profile and of everyone involved managers, teachers, and students (Behar, 2009; Piva et al., 2011).

An influential factor in the rupture of the educational model was the distance education courses, whose market has been growing rapidly in Brazil and around the world. This rapid growth shows the importance of this category when it comes to the discussion on quality education for all (Behar, 2009; Maia \& Mattar, 2007; Gonzales, 2014).

Rodrigo Fukugauti, Postgraduate in Education, Physical Education Teacher, Secretary of Education of the State of São Paulo, Comendador Emílio Romi State School (SEE/SP). 
However, even though the market is expanding in a quick pace, the same has not been happening with the development of human resources, since there still is not an adequate qualification and understanding of people's roles, their duties, responsibilities, and rights in the new process. Especially students who are not used to performing actively in the process are not able to respond effectively to the discipline and self-management of their learning (Maia \& Mattar, 2007).

Nevertheless, in order to participate efficient and adequately both in the process of online learning as in societal changes and transformations, basic competencies must be developed. They can be organized into three categories: "being able to act autonomously, being able to interact with socially heterogeneous groups, and being able to use resources and instruments interactively" (Rychen \& Salganik, 2001; 2003 as cited in Coll \& Monereo, 2010, p. 32).

That way, besides using new technologies in the educational process, it is also necessary to train and qualify students, so they can use these resources in their everyday lives (Gonzales, 2014), which is directly related to the concepts of e-literacy and information literacy. These concepts regard the ability to use and comprehend information in the most varied formats, from different sources presented through computers, and relate to the social role of knowledge and technology in society. In others words, students must be able to not only learn the functional use of technologies, but also participate adequately in the socio-cultural practices that these technologies provide in the society of information (Coll \& Monereo, 2010; Fukugauti, 2012; Coll, Mauri, \& Onrubia, 2010).

However, this process of change is not something natural and spontaneous (Gonzales, 2014), it must be an intentional act, planned, executed, and evaluated so that students have a positive experience (Horn \& Staker, 2015).

Within this setting, the motivation for the creation and implementation of the pilot project "e-du.c@c@o F1.51.C4: an experience in hybrid learning" came from the necessity of:

1. Adjusting the learning process and pedagogical management to the characteristics of the society of information;

2. Increasing credit hours in physical education classes due to the broad theoretical and practical content to be explored;

3. Promoting changes in school culture regarding the use of ICT, especially smart phones, as an important tool for the construction of the students' academic pathway and achievement of their life projects; and

4. Preparing students to continue their studies towards higher education, considering distance education courses as one of the qualification possibilities after high school.

According to Fukugauti (2017, p. 51),

This project is a personal initiative focusing on the curricular restructuring of physical education classes in high school, going beyond simple introduction of technological resources in pedagogical practices. The goal is to effectively integrate those resources in school everyday activities through the application of hybrid learning.

Hybrid learning, in turn, is a formal education program in which students learn in an integrated way through both face to face classroom teaching and online teaching, with a certain degree of control over location, time, manner, and/or pace of studying (Horn \& Staker, 2015; Bacich, Tanzi, \& Trevisani, 2015).

With the implementation of hybrid learning, combined with a learning model based on competence, the basis for a learning system focused on the student is formed. One allows them to develop the ability to conduct 
their own learning, becoming a perpetual learner. Such characteristics are essential to their performance in contemporary society, where changes occur rapidly, turning knowledge and abilities obsolete at the same speed (Horn \& Staker, 2015).

In becoming the focus of the learning process, students create a sense of performance and ownership over their progress, being able to learn at any moment, anywhere, at any pace, and any way. In other words, it allows the individualization and personalization of the learning process. It makes possible for them to map out different paths in order to reach a common destination (Horn \& Staker, 2015; Bacich, Tanzi, \& Trevisani, 2015).

So that the experiences tied to the changes in educational paradigms can be replicated in other contexts, it is important to develop scientific researches to assist in the understanding of these new trends by means of production of a new knowledge, which will respond to these changes (Behar, 2009).

Taking into account the results from the research made by Whelan and Plass (2002, as cited in Piva et al., 2011), 217 articles analyzed in relation to the educational use of the web for online education, in which most ( $n$ $=138,63 \%$ ) were not of empirical nature. According to the results obtained by Fukugauti (2012), 681 publications analyzed, in which the minority $(n=109,16 \%)$ had research-action as the methodological orientation and less than half of it $(n=47,43 \%)$ had been developed in the field of education. The necessity to amplify scientific production based on empirical studies in this field of knowledge proves itself urgent, so that the innovations can achieve relevance and promote improvement in the quality of education.

\section{The Methodological Approach}

The methodology used for the elaboration of this paper included:

1. Indirect documentation, by means of bibliographical research, carrying out a survey of relevant publications, and through documental research, consulting the school's private files as well as the teacher responsible for the pilot project.

2. Direct documentation through field research, featured as program evaluation studies and relations between variables, of the quantitative-descriptive kind.

3. Intensive direct observation, by means of systematic, unsystematic, participant, and individual observation also performed in real life (Markoni \& Lakatos, 2003).

The sample was composed by non-probabilistic sampling by typicality and taking into consideration that the implementation of the pilot project promoted intentional changes in the environment, this paper is also characterized as a case study, carried out by means of research-action (Markoni \& Lakatos, 2003; Severino, 2007; Thiollent, 1986).

The collected data are of qualitative and quantitative nature. The quantitative data were analyzed through descriptive statistics and the Pearson correlation. For the strength of the coefficient and correlation, consider: (a) > 0.90-very high; (b) 0.70-0.89-high; (c) 0.50-0.69-intermediate; (d) 0.30-0.49-low; and (e) < 0.30-little or no correlation (Markoni \& Lakatos, 2003; Tritschler, 2003).

\section{Results}

The pilot project, which is the object of analysis in this paper, began in 2016, completing two years of implementation in 2017.

The educational activities developed with the students through this pilot project were structured according to the rotation model called inverted classroom, one of the hybrid learning models. The rotation takes place 
between home or another location outside the school, where students do their online activities, and school where the teacher supervises their practice (Fukugauti, 2016; Fukugauti, 2017; Horn \& Staker, 2015; Bacich, Tanzi, \& Trevisani, 2015).

The online activities were made available via the application Google Classroom, which can be accessed by both the browser (classroom.google.com) and the application for tablets or smart phones (Fukugauti, 2016; Fukugauti, 2017).

Due to the lack of previous experience in that direction at the school where the pilot project has been implemented, the decision was taken to work with a sustained innovation model, which comes closer to the traditional format. That way, bearing in mind the use of disruptive methodologies in the future, the transition process would not cause strangeness and resistance from the students, and consequently, negative results (Fukugauti, 2016).

However, things did not go as planned. What seemed to be something that would address the students' needs for more dynamic activities and active methodologies brought along conflicts and resistance from the students as an initial result of the innovation process.

According to Simão (2010, pp. 37-38), "Resistance to change is common to most societies, even if there is a desire for the new. While we know and feel the need for change, many of us fear possible alterations." The following results show it clearly.

All registered students regularly attending classes in 2016 and 2017 were part of this research. Generally speaking, there was a small variation in the number of students every bimester:

1. In 2016, there were 479 registered students in the first bimester, 480 students in the second bimester, and 473 students in the third and fourth bimester; and

2. In 2017, there were 515 registered students in the first bimester, 507 students in the second bimester, 500 students in the third bimester, and 499 students in the fourth bimester.

The first indicator to be observed is the number of registered students via the application Google Classroom. Since in the first bimester of 2016 the teacher responsible enrolled every student, $100.00 \%$ were registered and the goal regarding this indicator was established only in the second bimester of the same year, taking into account a small amount in the beginning, but that would increase as time went by.

As shown in Figure 1, in 2016, even though there was an inversely proportional relation regarding the goal $(r=-0.91)$, the second and third bimester overcame the goals established for these periods. However, in the fourth bimester, the number of registered students in the class was smaller than the established goal.

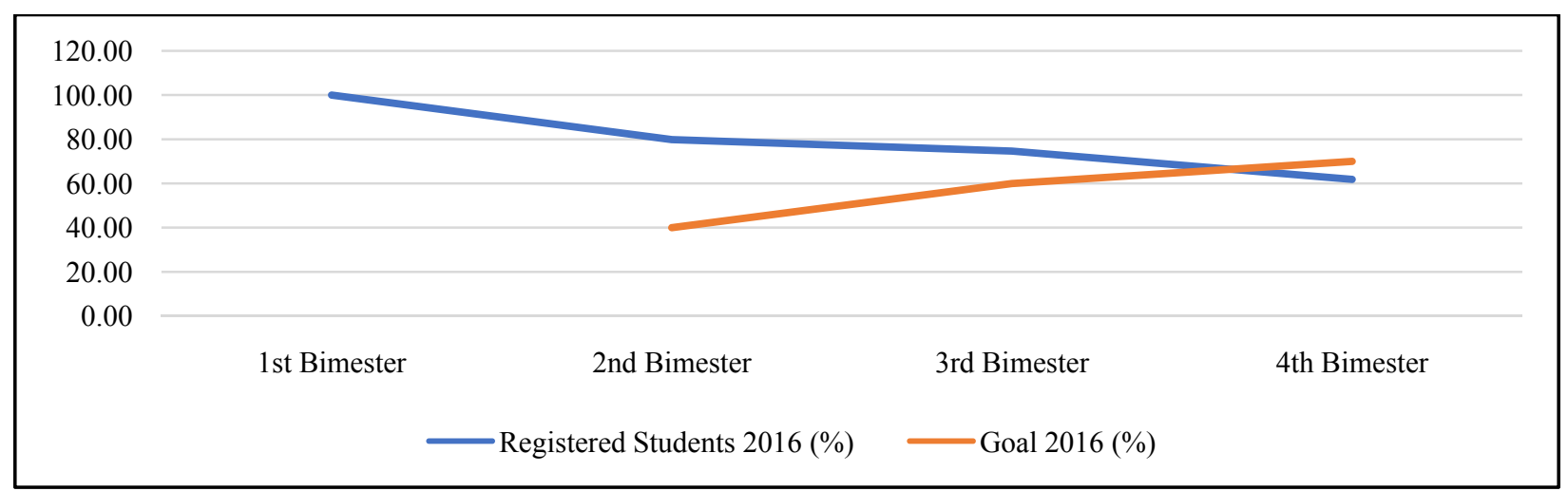

Figure 1. Relation between registered students and goal in 2016. 
In 2017, Figure 2 shows that throughout the whole school year the number of registered students was bigger than the established goal for this indicator, showing a behavior closer to the expected $(r=0.78)$, even though there was a negative variation from the second to the third bimester.

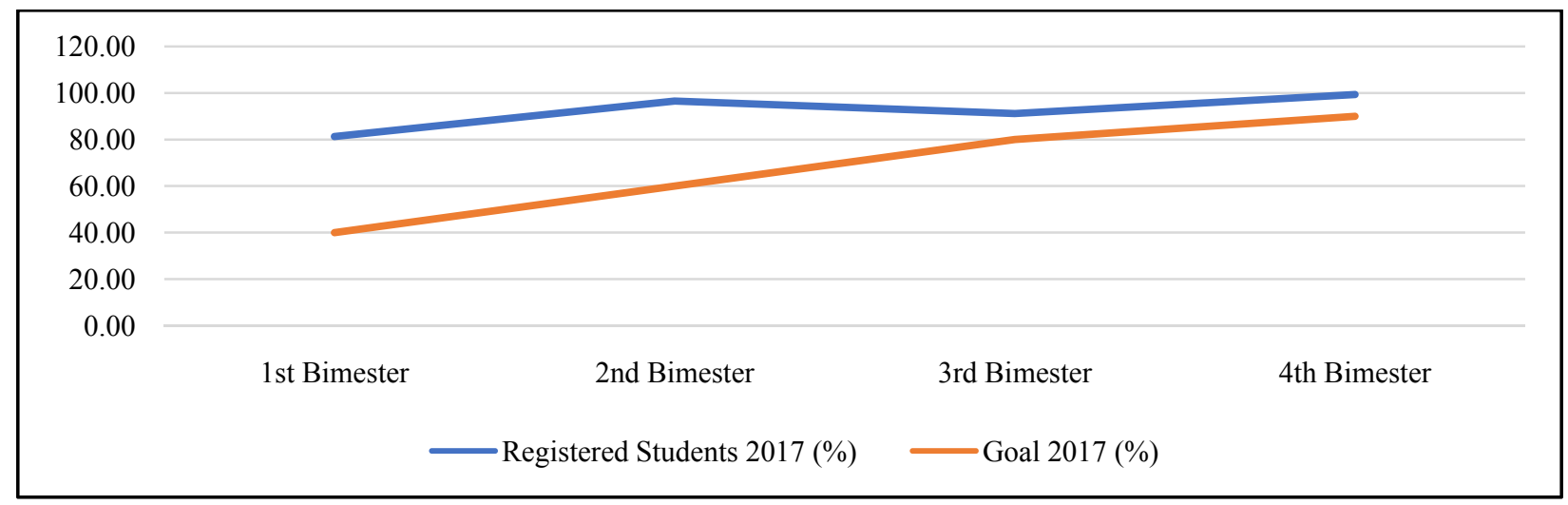

Figure 2. Relation between registered students and goal in 2017.

The same behavior can be observed regarding the number of online activities performed by the students. While in 2016 there was an inversely proportional relation $(r=-0.94)$ between the goal and the result obtained, as shown in Figure 3. According to Figure 4, in 2017 this relation is directly proportional $(r=0.87)$ with the difference that this indicator remains lower than the established goal for most of the time.

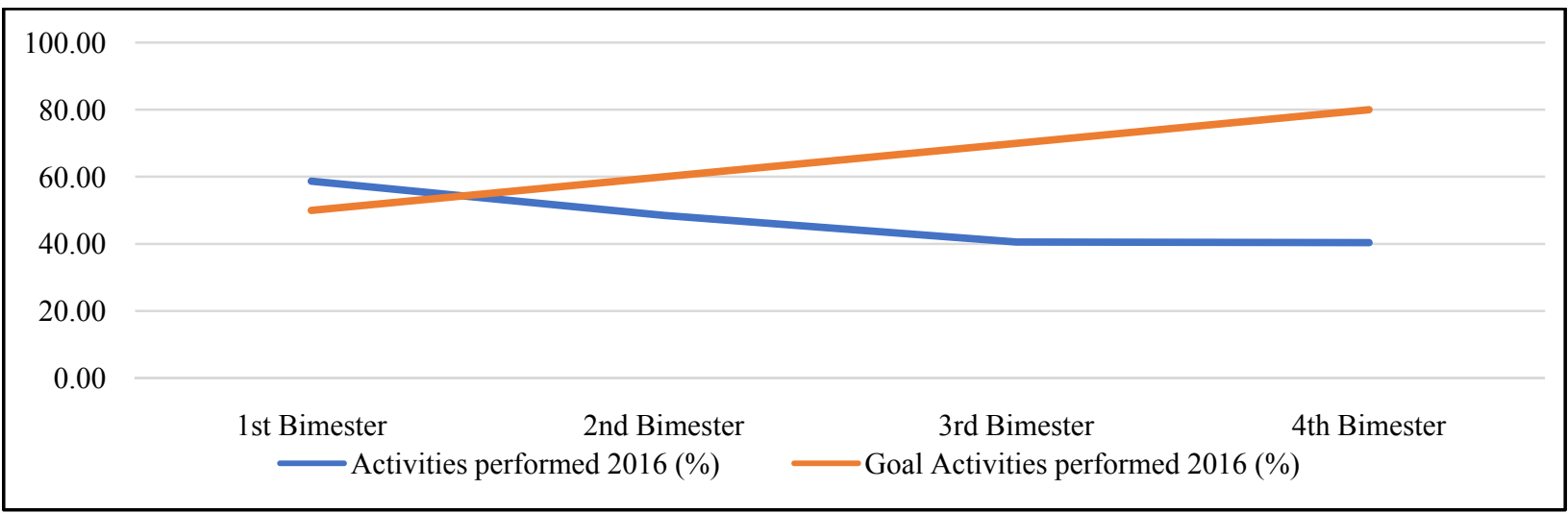

Figure 3. Relation between Activities performed and Goal in 2016.

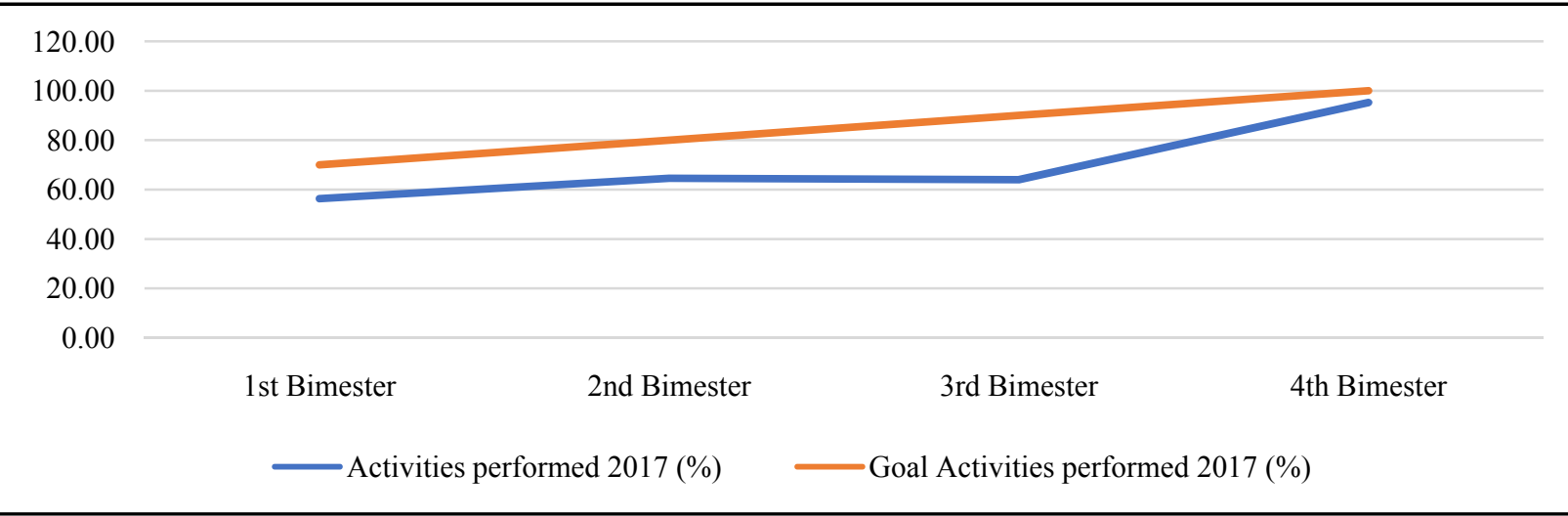

Figure 4. Relation between Activities performed and Goal in 2017. 
When comparing the number of students registered via the application and the amount of online activities done in the two years, as shown in Figures 5 and 6, there is an inversely proportional relation in both cases ( $r=$ $-0.91, r=-0.66$ ). While in 2016, negative results were obtained, as shown in figures through decreasing curves. In 2017, positive results were obtained, as shown in the figures through predominantly increasing curves. By the end of the last year, on average, $99(39 \%)$ of the total of students were registered in the class via the application and 95 (24\%) of the online activities had been done.

In order to better understand the behavior of the indicators shown previously, the students' performance in class can explain the reason why such variations occurred. In 2016, since it was the beginning of the implementation of the pilot project, in which the adaptation process was taking place among the teacher and the students as far as changes in school culture are concerned, the activities did not weigh much on the students' summative evaluation.

That means the online activities added up to the participation score along with the other activities (the participation score corresponded to the percentage of activities done in relation to the total) and this score corresponded to only a third, a fourth, or a fifth of the final score, depending on the case.

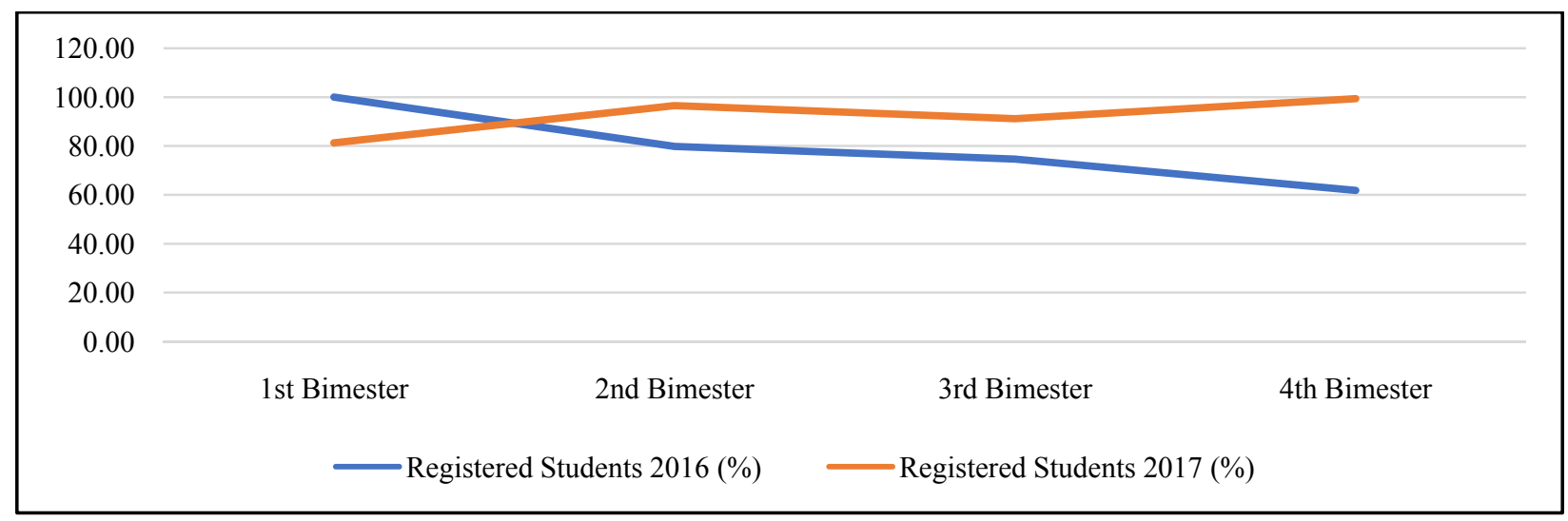

Figure 5. Comparison between registered students in 2016 and 2017.

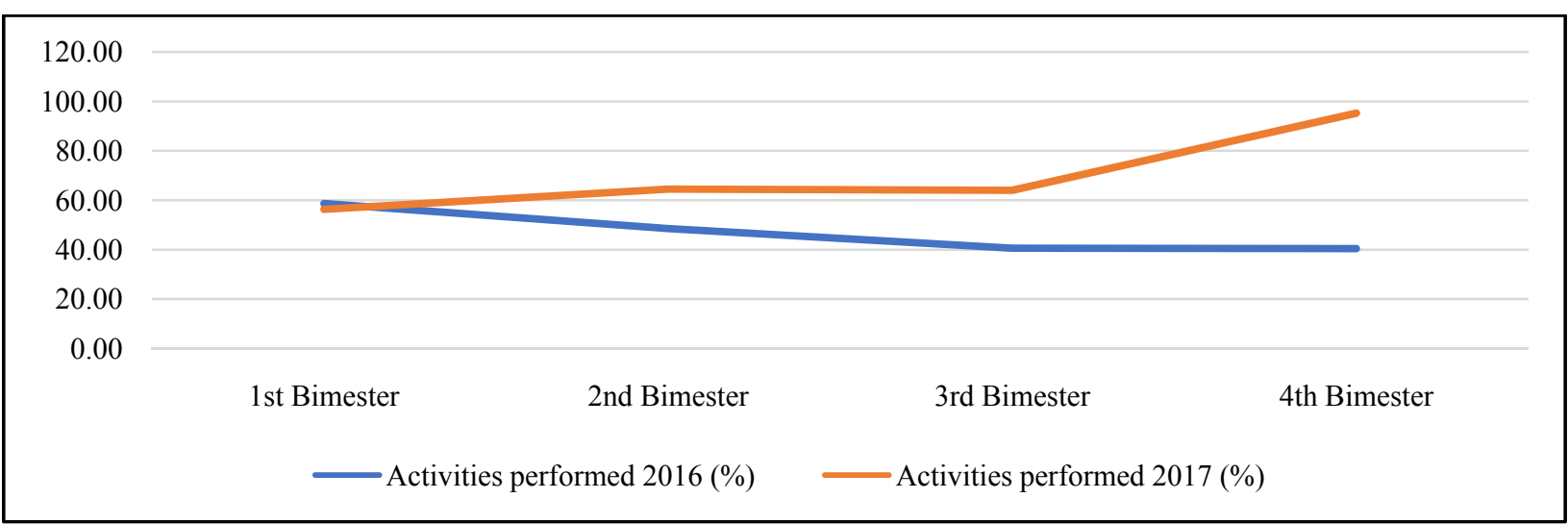

Figure 6. Comparison between activities performed in 2016 and 2017.

Without a doubt, this explains the students' performance shown in Figure 7, for even though there was a decrease in the number of registered students via the application and in the number of online activities done by the students in 2016, the amount of students with sufficient performance was always close to $100.00 \%$. 


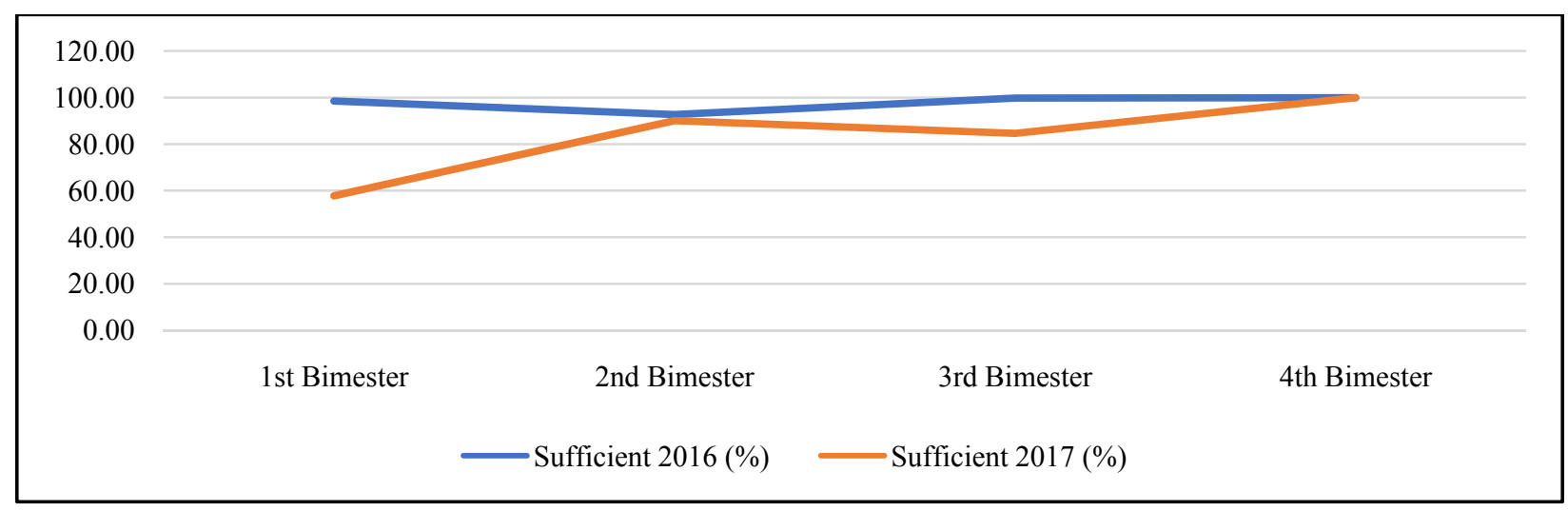

Figure 7. Comparison between the students' performance in 2016 and 2017.

In 2017, however, the online activities started weighing much more on the summative evaluation of the class, being determinant on the final score, and giving students a "reality check", for only $57.84 \%$ had achieved a sufficient performance by the end of the first bimester. In other words, almost half the students obtained insufficient performance on account of not doing the online activities and believing the evaluation criteria would be the same as the year before, even though the teacher had explained and reminded them every class.

In face of this result, an approach was planned in order to solve the problem by means of a standby support in the computer room where students were assisted during lunchtime, with previous scheduling defining the priority of assistance, or without previous scheduling requesting help and being assisted according to the teacher's availability.

This practice produced positive, yet not very encouraging results, because although the students' performance had increased abruptly in the second bimester, it was due to a larger concentration of practical activities, bearing in mind that the amount of online activities done by the students was only slightly higher.

In the third bimester, with the decrease in practical activities and the maintenance of the amount of online activities, there was a small decline in the students' performance.

In the fourth bimester, with the realization that many students had not done the online activities, or had partially completed them, and taking into consideration that many of them did not obtain a sufficient performance in the previous bimesters, another intervention was made necessary.

Only this time with moments of intensive recovery, only the students who had not done the online activities should attend. Along with this measure, the students with insufficient performance in the previous bimesters had to do all the activities they had not done along the year, with a continuous recovery along the fourth bimester.

These measures resulted in another "reality check" for the students, who realized the importance of doing the online activities in order to build a sufficient performance for their approval in that class.

These "reality checks" to which the students have been exposed during the consolidation process of the pilot project were consisted of extrinsic motivations, which are useful to "create habits, routines, and procedures, and it is important that it be internalized by the students themselves" (Moran, 2015, p. 31).

In support to all that has been shown, Figure 8 presents the relation between the amount of online activities and the students' performance in 2017, validating the directly proportional relation $(r=0.78)$ between these two indicators, suggesting that the larger the number of activities done by the students is, the higher the performance is. In the bimesters, in which the number of practical and face-to-face classroom activities that 
formed the summative evaluation was higher than the amount of online activities, the students' performance was also higher.

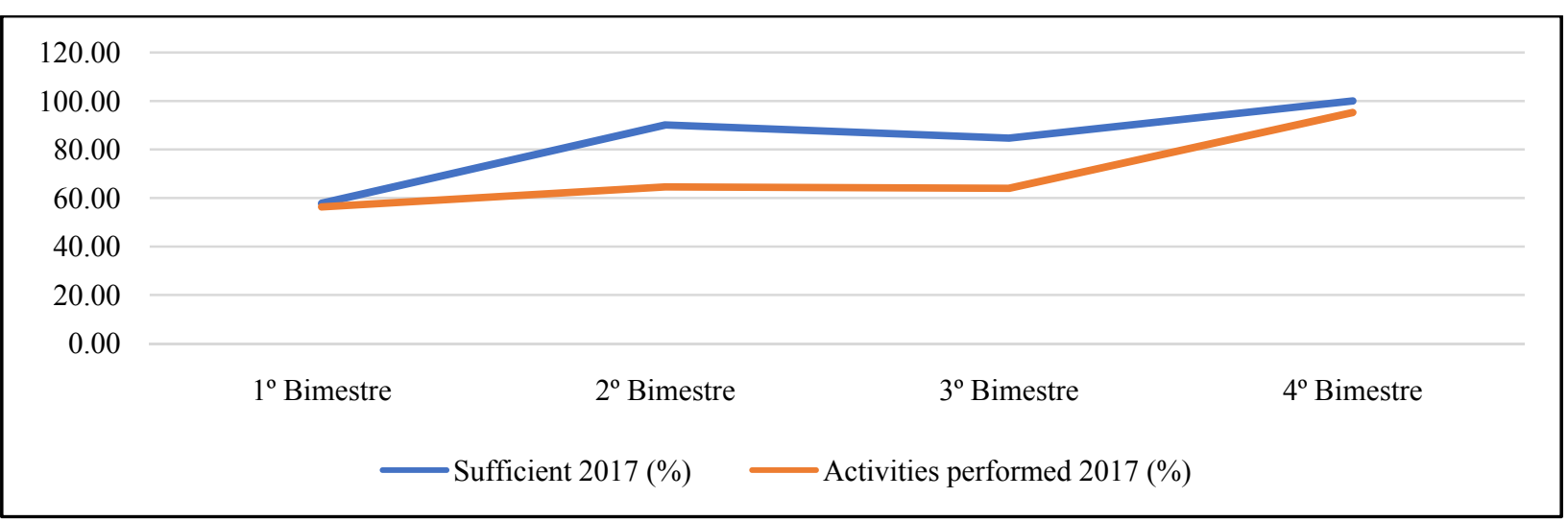

Figure 8. Relation between the number of activities and the students' performance in 2017.

Moreover, from 2016 to 2017, there was an increase. On average, of 26 (11\%) in the amount of online activities proposed to the students (a few, however, were done in the classroom) and twice the positive outcome rather than negative outcome in the $360^{\circ}$ evaluation regarding the pilot project.

In 2016, from a total of 21 comments considering both evaluations, only two were negative ( $9.52 \%)$, while five were positive $(23.81 \%)$, and in 2017 , from a total of 59 comments, only nine were negative (15.25\%), while 19 were positive $(32.20 \%)$.

Finally, it is worth noting that the teacher made himself completely available to assist the students on the technical and pedagogical aspects related to the learning process.

The assistance could happen at any moment, at the school (during classes, breaks, and during lunchtime) or via Facebook, Whatsapp, email, Google Classroom, and other applications, which allowed for synchronous or asynchronous communication, outside of school hours (at night, weekends, and holidays). That way, the teacher performed several functions: tutor, counselor, moderator, assistant, mentor, enabler, etc. (Mauri \& Onrubia, 2010; Horn \& Staker, 2015).

In 2016, the distance assistance was much more intense in the beginning of the implementation process of the pilot project. As time went by, the need for assistance decreased significantly and by the end of 2017, only a few students reached out to the teacher for guidance and questions about the activities. As stated by Horn and Staker (2015), the culture, which is formed by repetition, exercises such power that when an organization reaches a common paradigm, it becomes self-manageable and autonomous. Resisting, insisting, and persisting are necessary so that a new model becomes concrete and carries on as a culture.

All these results suggest that the pilot project is strengthening as school culture, promoting changes in the learning-teaching dynamics and the role of the teacher and students involved in the learning process, which includes the creation of collaborative learning communities.

\section{Conclusion}

Every change causes discomfort. Evidently, it would not be different with the pilot project under study. However, even though the acceptance of the online activities is not yet unanimous among the students, the initial resistance is being overcome. 
In fact, it was only through a "reality check" and creating intensive extrinsic motivation in the students that the indicators started showing progress. Considering the results presented, that is why the consolidation process of the pilot project as school culture seems to have begun and is currently in progress, confirming the planned hypothesis in certain aspects and even surpassing them in others.

The inclusion of technologies in the school context is part of the general competencies of the National Common Curriculum Base (Ministry of Education, 2017) approved recently by the National Board of Education. Schools and teachers can no longer ignore the importance of implementing innovations in the learning process.

Re-signifying school activities from a pedagogical, methodological, and operational point of view is necessary in order to prepare students adequately so they can perform in society today. Otherwise, schools will not be fulfilling their social role.

In adjusting schoolwork to the new demands of the present, the inclusion of technologies and the re-signification of the formative context, schools will be heading towards improvement in the students' conditions of access to cultural assets and materials historically produced by humanity. It will be providing the individualization and personalization of education, attending to the specific needs of each student, increasing productivity in the learning process, and above all, it will be acting in a way of promoting social justice by giving opportunities to those who need it most, especially students from public schools.

\section{References}

Bacich, L., Tanzi, A. N., \& Trevisani, F. de M. (Eds.). (2015). Ensino Híbrido: Personalização e tecnologia na educação (Hybrid Learning: Personalization and technology in education) (pp. 44-60). Porto Alegre: Penso.

Behar, P. A. (Eds.). (2009). Modelos pedagógicos em educação a distância (Pedagogical models in distance education) [electronic resource]. Porto Alegre: Artmed.

Coll, C., Mauri, T., \& Onrubia, J. (2010). A incorporação das tecnologias da informação e da comunicação na educação: Do projeto técnico-pedagógico às práticas de uso (The incorporation of information and communication technologies in education: From the technical-pedagogical project to the practices of use). In C. Coll, \& C. Monereo (Eds.), Psicologia da educação virtual: aprender e ensinar com as tecnologias da informação e da comunicação (Psychology of virtual education: Learning and teaching with information and communication technologies) (electronic resource, pp. 66-93). Porto Alegre: Artmed.

Coll, C., \& Monereo, C. (Eds.). (2010). Educação e aprendizagem no século XXI: Novas ferramentas, novos cenários, novas finalidades (Education and learning in the 21st century: New tools, new scenarios, new purposes). In Psicologia da educação virtual: aprender e ensinar com as tecnologias da informação e da comunicação (Psychology of virtual education: Learning and teaching with information and communication technologies) (electronic resource, pp. 15-46). Porto Alegre: Artmed.

Fukugauti, R. (2012). Google drive: Uma ferramenta de gestão burocrático-pedagógica a serviço da escola? O início de um trabalho (Google drive: A bureaucratic-pedagogical management tool at the service of the school? The beginning of a work). São Paulo: REDEFOR/USP.

Fukugauti, R. (2016).E-du.c@c@o F1.51.C4: Uma experiência a partir do Ensino Híbrido (E-du.c@c@o F1.51.C4: An experience in Hybrid Learning). Rio de Janeiro: LANTE/UFF.

Fukugauti, R. (2017).E-du.c@c@o F1.51.C4: Uma experiência a partir do ensino híbrido (E-du.c@c@o F1.51.C4: An experience in Hybrid Learning). Coleção Pesquisa em Educação Física (Physical Education Research Collection), 16(2), 49-58.

Gonzales, J. (2014). Educação a distância: Neoprodutivismo, Novas Tecnologias e Compromisso Político (Distance education: Neoprodutivism, New Technologies and Political Commitment) [electronic resource]. Retrieved from https://www.saraiva.com.br/educacao-a-distancia-neoprodutivismo-novas-tecnologias-e-compromisso-politico-6741625.html

Horn, M. B., \& Staker, H. (2015). Blended: Usando a inovação disruptiva para aprimorar a educação (Blended: Using Disruptive Innovation to Improve Schools). Porto Alegre: Penso.

Maia, C., \& Mattar, J. (2007). ABC da EaD (ABC of the distance education) (1st ed.). São Paulo: Pearson Prentice Hall. 
Marconi, M. de A., \& Lakatos, E. M. (2003). Fundamentos de metodologia científica (Fundamentals of scientific methodology) (5th ed.). São Paulo: Atlas.

Mauri, T., \& Onrubia, J. (2010). O professor em ambientes virtuais: Perfil, condições e competências (The teacher in virtual environments: Profile, conditions and competences). In C. Coll, \& C. Monereo (Eds.), Psicologia da educação virtual: aprender e ensinar com as tecnologias da informação e da comunicação (Psychology of virtual education: Learning and teaching with information and communication technologies) (electronic resource, pp. 118-135). Porto Alegre: Artmed.

Ministry of Education. (2017). Base Nacional Comum Curricular: Educação é a base (National Curricular Common Base: $\begin{array}{lllll}\text { Education } & \text { is } & \text { basis). } & \text { Retrieved }\end{array}$ http://basenacionalcomum.mec.gov.br/wp-content/uploads/2018/02/bncc-20dez-site.pdf

Moran, J. (2015). Educação Híbrida: Um conceito-chave para a educação, hoje (Hybrid Education: A Key Concept for Education Today). In L. Bacich, A. N. Tanzi, \& F. de M. Trevisani, (Eds.), Ensino Híbrido: Personalização e tecnologia na educação (Hybrid Learning: Personalization and technology in education) (pp. 26-43). Porto Alegre: Penso.

Piva, D. Jr., Pupo, R., Gamez, L., \& Oliveira, S. (2011). EAD na Prática: planejamento, métodos e ambientes (EAD in Practice: Planning, methods and environments) [electronic resource]. Rio de Janeiro: Elsevier.

Severino, A. J. (2007). Metodologia do trabalho científico (Methodology of scientific work) (23 ed.). São Paulo: Cortez.

Simão, A. N. (2010). Cenários e Modalidades da EAD (Scenarios and Modalities of EAD). Curitiba: IESDE Brasil S.A.

Thiollent, M. (1986). Metodologia da pesquisa-ação (Action research methodology). São Paulo: Cortez/Autores Associados.

Tritschler, K. A. (2003). Medida e avaliação em educação física e esportes de Barrow \& McGee (Barrow \& McGee Measurement and Assessment in Physical Education and Sports) (5th ed.). Barueri, SP: Manole. 